\title{
Intergenerational Trauma in Aboriginal Peoples
}

\section{The Importance of Understanding Historical Context as a Health Professional}

Peter Cordell (Meds 2016)

Faculty Reviewer: Dr Tara Somerville, MD

\section{BACKGROUND INFORMATION}

Aboriginal peoples (First Nations, Inuit, and Metis peoples) represent approximately $4 \%$ of the Canadian population ${ }^{1}$ and $1.7 \%$ of the population in the region served by the Southwest Local Health Integration Network (LHIN). ${ }^{2}$ In fact, Aboriginal peoples are the fastest growing population in Canada, ${ }^{2}$ with an average age that is significantly younger than that of the non-Aboriginal population. ${ }^{1}$ However, Aboriginals face higher rates of chronic disease and a variety of challenges accessing care and therefore deserve particular attention. ${ }^{2}$ Although many efforts are underway to improve health outcomes in Aboriginals, their health outcomes are still disproportionately poor in comparison to those of non-Aboriginal Canadians. ${ }^{3}$

Awareness of this disparity is not only important to health professionals practicing in Northern Ontario, but also to those in the Southwest LHIN region, due to the number of Aboriginal people residing in this region. ${ }^{2}$ In London alone there are 4590 persons identified as First Nations people, another 1345 identified as Métis, and 80 identified as Inuit. ${ }^{4}$

\section{CASE PRESENTATION}

A 19-year-old male from an Ontario First Nations community presented for an appointment with his family physician at the local health centre complaining of arm pain. The patient had visited the local emergency room the day prior, but had been quickly released as his injuries were not the result of a fracture.

The family physician assessed the patient's injuries, which appeared to be the reason for his appointment. However, further discussion revealed that the individual's partner was physically violent and that the trend was escalating. On examination, the physician noted several abrasions, a cigarette burn, and a contusion on the patient's back. After treating the injuries, the individual's current living situation and safety were discussed. The individual described his willingness to end this abusive relationship and an action plan was created. Later in the appointment, as the patient felt more comfortable, he explained that he had considered suicide. His immediate risk of suicide was assessed and the reasons behind his suicidal ideation were explored.

The individual had an extensive history of witnessing and experiencing domestic violence in his childhood, as did his partner. The challenge, the physician described, is that in order to enter a healthy relationship, one must know what that looks like, whereas in this case, both individuals understood relationships in the context of abuse and violence as this was their environment as children.

\section{CULTURAL SAFETY}

Cultural safety involves health professionals' recognition that they bring their own culture and attitudes to the relationship with the patient and need to be respectful of the patient's nationality, culture, age, sex, political and religious beliefs, and sexual orientation. ${ }^{5}$ In order to achieve cultural safety, health professionals must learn to move beyond the concept of cultural awareness - being aware that a difference exists-to analyzing power imbalances, institutional discrimination, colonization, and colonial relationships as they apply to health care. ${ }^{5}$

Recognition of the health disparity between Aboriginals and non-Aboriginals is critical for practitioners to adjust screening and treatment practices accordingly. However, this awareness can be harmful if it leads to the impression that Aboriginal people are inherently sick. ${ }^{6}$ Such an impression puts health professionals at risk of blaming Aboriginal people for their health status. ${ }^{3}$

\section{ABUSE AND INTERGENERATIONAL TRAUMA}

Sources of intergenerational trauma due to colonization include residential schools, forced relocation, involuntary sterilization, forced adoption, religious conversion, and enfranchisement. ${ }^{1}$ For example, residential school survivors experienced trauma through the abuse and violence that took place in the schools. ${ }^{7}$ Testimony from former students reveals the extremely harsh and hazardous living conditions at the schools, including hunger and malnutrition, poor heating and sanitation, inadequate clothing, and exposure to contagious diseases. ${ }^{8}$ Furthermore, many students suffered sexual, physical, and emotional abuse by the teachers and staff responsible for their care. ${ }^{8}$ The lack of proper treatment and conditions in the schools contributed to the deaths of thousands of children. ${ }^{8}$ This experience enacts its intergenerational effects through the relationship between trauma and future family violence and abuse.

Domestic violence and abuse are almost always linked to trauma. ${ }^{7}$ It is estimated that 3.2 million American children witness incidents of domestic violence annually. ${ }^{9-10}$ When children grow up witnessing violence and abuse, they are far more likely to be violent themselves or to enter into abusive relationships. ${ }^{7}$ In fact, child witnesses have been found to display inappropriate attitudes about violence as a means of resolving conflict and indicate a greater willingness to use violence themselves., ${ }^{9,11,12,13}$ In the long-term, the future parenting and relationship skills of children are at stake. ${ }^{14}$ Thus, trauma is both one of the primary causes as well as a principal outcome of domestic violence and abuse. ${ }^{7}$ This creates a challenging cycle to break due to its intergenerational effects. ${ }^{7}$ 


\section{CASE REPORT}

In 1999 Statistics Canada found that 25\% of Aboriginal women and $13 \%$ of Aboriginal men reported experiencing violence from a current or previous partner over the past five years ${ }^{7}$ - the national average was $8 \%$ and $7 \%$ in Canadian women and men, respectively, over the same period ${ }^{7}$. Subsequently, in 2009 Statistics Canada found that Aboriginal women were 3 times as likely as non-Aboriginal women to experience spousal abuse. ${ }^{15}$ This is especially alarming given that reports are much less frequent than the violence itself. ${ }^{14}$ The critical point to understand is that the current statistics on domestic violence and abuse in Aboriginals is intimately related to the intergenerational trauma sustained through colonization. This is demonstrated through the abuse cycle initiated by residential school survivors that have experienced violence and abuse.

\section{DISCUSSION}

It is extremely important to understand the inequities and statistics regarding various illnesses and diseases in Aboriginal peoples. However, when risk factors are removed from their historical, social, and economic contexts, there is a potential to encourage or reinforce the development of negative stereotypes. ${ }^{1}$ Health professionals must recognize that colonization is a root cause of the negative health outcomes in Aboriginals. ${ }^{3}$ This recognition helps prevent the blaming of Aboriginal patients for their health-related behaviours. $^{3}$

The experience of many Aboriginal People with the mainstream health care system has been negative, often due to cultural differences. ${ }^{5}$ Frequently, cultural differences and the inability of health professionals to appropriately address these in a culturally safe manner have contributed to high rates of noncompliance and reluctance to visit mainstream health facilities. ${ }^{5}$ Consequently, this has left Aboriginal patients with feelings of fear, disrespect and alienation. ${ }^{5}$ Cultural safety conversely entails respectful communication, empowers the patient, and improves quality of care. ${ }^{5}$

Due to the inherent power imbalance present in the health-professional-to-patient relationship, ${ }^{1}$ it is the responsibility of the health professional to pursue training in cultural safety as it pertains to Aboriginal peoples. This knowledge is especially important given the health inequity faced by Aboriginals, as well as the aforementioned population demographics for the Southwest LHIN region.

In conclusion, it is critical for health professionals to be aware of the difference in health outcomes in Aboriginal peoples, while being sure not to stereotype Aboriginal patients based on these statistics. ${ }^{3}$ Health professionals must work together with Aboriginal communities to provide community-directed and culturally safe solutions that disrupt the cycle of abuse stemming from colonization.

\section{REFERENCES}

1. Wilson D, et al. Health professionals working with First Nations, Inuit, and Metis consensus guideline. J Obstet Gynaecol Can. 2013 Jun;35(6):13-41.

2. South West LHIN. South West LHIN IHSP 2010-2013: Appendix J: Aboriginal population profile [Internet]. London (ON): South West LHIN; 2009 Nov 30 [cited 2013 Aug 31]. Available from: http://www.southwestlhin.on.ca/uploadedFiles/Pub-
lic_Community/Integrated_Health_Service_Plan/2009_IHSP/ Appendix\%20J\%20-\%20Aboriginal\%20Profile\%20FINAL.pdf

3. Baker AC, Giles AR. Cultural Safety: A framework for interactions between Aboriginal patients and Canadian family medicine practitioners. J Aborig Health. 2012 Nov;9(1):15-21.

4. Statistics Canada. 2006 Aboriginal population profile for London [Internet]. Ottawa: Statistics Canada; 2010 Mar 24 [cited 2013 Aug 30]. Available from: http://www.statcan.gc.ca/ pub/89-638-x/2009001/article/10828-eng.htm.

5. National Aboriginal Health Organization. Cultural competency and safety: a guide for health care administrators, providers and educators. Ottawa: National Aboriginal Health Organization; 2008 Jul [cited 2013 Aug 20]. Available from: http://www.naho. ca/documents/naho/publications/culturalCompetency.pdf

6. Elliot CT \& de Leeuw SN. Our aboriginal relations: When family doctors and aboriginal patients meet. Can Fam Physician. 2009 Apr;55(4):443-4.

7. Bopp M, Bopp J, Lane P Jr. Aboriginal domestic violence in Canada [Internet]. Ottawa: Aboriginal Healing Foundation; 2003 [cited 2013 Aug 20]. Available from: http://site.ebrary.com. proxy2.lib.uwo.ca/lib/uwo/docDetail.action?docID=10082945

8. Troniak S. Addressing the legacy of residential schools [Internet]. Ottawa: Library of Parliament; 2011[cited 2013 Sep 6]. Available from: http://www.parl.gc.ca/Content/LOP/ResearchPublications/2011-76-e.pdf

9. Stiles MM. Witnessing domestic violence: the effects on children. Am Fam Physician. 2002 Dec;66(11):2052-67.

10. Roberts AR. Battered women and their families: intervention strategies and treatment programs. New York: Simon \& Schuster; 1984.

11. Jaffe PG, Hurley DJ, Wolfe D. Children's observations of violence: I. Critical issues in child development and intervention planning. Can J Psychiatry. 1990 Aug;35(6):466-70.

12. Jaffe PG, Wolfe D, Wilson S, Zak L. Similarities in behavioural and social maladjustment among child victims and witnesses to family violence. Am J Orthopsychiatry. 1986 Jan;56(1):142-6.

13. Spaccarelli S, Coatsworth JD, Bowden BS. Exposure to serious family violence among incarcerated boys: its association with violent offending and potential mediating variables. Violence Vict. 1995 Fall;10(3):163-82.

14. National Clearinghouse on Family Violence (Canada). Aboriginal women and family violence [Internet]. Ottawa: National Clearinghouse on Family Violence; c2008 [cited 2013 Sep 2]. Available from: http://books.scholarsportal.info/viewdoc. html?id $=365778$

15. Brennan S. Violent Victimization of Aboriginal Women in the Canadian Provinces, 2009 [Internet]. Ottawa: Statistics Canada; 2011 May 17 [cited 2013 Sep 2]. Available from: http://www. statcan.gc.ca/pub/85-002-x/2011001/article/11439-eng.htm 